\title{
Novel Method for the Quantification of Ropinirole Hydrochloride in Pure API and its Marketed Formulations Using 3-Methyl-2-benzothiazolinone Hydrazone Hydrochloride and $p$-Dimethylamino- cinnamaldehyde as Chromogenic Reagents by Spectrophotometry
}

\author{
I. SRIKANTH ${ }^{1 *}$, M. SRILATHA ${ }^{1}$, P. RATNA KUMARI ${ }^{1}$ P. V. SURESH ${ }^{2}$
}

${ }^{1}$ Department of Pharmaceutical Analysis, K.C. Reddy Institute of Pharmaceutical Sciences, Jangamguntla Palem, Medikonduru Mandal, Guntur 522 348, India

${ }^{2}$ Department of Pharmaceutical Analysis, Chalapathi Institute of Pharmaceutical Sciences, Chalapathi Nagar, Lam, Guntur 522 034, India

chrissrikant@gmail.com

Received 4 June 2017 / Accepted 28 June 2017

\begin{abstract}
Two novel simple and sensitive spectrophotometric methods in visible region were developed for the estimation of ropinirole hydrochloride (RPH) in pure and its pharmaceutical dosage forms. Method-A based on the oxidative coupling product with 3-methyl-2-benzothiazolinone bydrazone bydrochloride (MBTH) in presence of ferric chloride to give intense blue colored azodye complex having $\lambda_{\max }$ at $680 \mathrm{~nm}$ and method-B based on the reaction of $p$-dimethylaminocinnamaldehyde (PDAC) under acidic media to give yellow colored Schiff base having $\lambda_{\max }$ at $420 \mathrm{~nm}$. Both these methods obey Beer's law in the concentration range of 5-50 $\mu \mathrm{g} / \mathrm{mL}$. All variables in these methods are optimized and the reaction mechanisms are presented. No interference was observed from tablet additives and the applicability of these methods was examined by analyzing tablets containing RPH. The proposed methods are precise, accurate and reproducible. It can be extended to the analysis of ropinirole hydrochloride in marketed formulations.
\end{abstract}

Keywords: Chromogen, MBTH, PDAC, Ropinirole hydrochloride, Spectrophotometry

\section{Introduction}

Ropinirole hydrochloride (RPH) (Figure 1) is chemically named as 4-[2-(dipropylamino)ethyl]-1, 3 -dihydro- $2 \mathrm{H}$-indol-2-one, it is an anti parkinsonian agent (Dopamine agonist) and also used to treat restless legs syndrome. It is a white to yellow solid with a melting range of 243 to $250{ }^{\circ} \mathrm{C}$ and a solubility of $133 \mathrm{mg} / \mathrm{mL}$ in water. From extensive literature survey reveals that the drug can be estimated by various spectrophotometric methods like visible ${ }^{1}$, ultra-violet $^{2,3}$, 
spectrofluorimetry ${ }^{2}$, chromatographic methods like RP-HPLC ${ }^{4,6}$, LC-UV $^{5}$, HPTLC $^{3}$, UPLC $^{7}$ and also combination of chromatographic and spectrophotometric method, LC-MS/MS were developed in biological fluids and pharmaceutical formulations. The drug isolated from impurities by capillary liquid chromatography, capillary electrophoresis ${ }^{9,10}$, chemometric evaluation method ${ }^{11}$.

Spectrophotometry is the most common and convenient analytical tool due to its inherent simplicity and low costing. It is used in most of the quality control and clinical laboratories. A very few visible spectrophotometric methods were developed with different chromogens. The main aim of this study was to develop two simple, sensitive spectrophotometric methods for quantification of RPH by using MBTH and PDAC in pure and its marketed formulations. The proposed methods for the quantification of RPH were successfully validated as per ICH guidelines ${ }^{12,13}$.<smiles>CCCN(CCC)CCc1cccc2c1CC(=O)N2</smiles>

\section{Experimental}

Figure 1. Structure of ropinirole hydrochloride

A Systronics UV-Visible spectrophotometer model AU-2701 with $10 \mathrm{~mm}$ matched quartz cells were used for all spectral measurements and for $\mathrm{pH}$ measurements using ELICO digital $\mathrm{pH}$ meter model-LI 127. The API, ropinirole hydrochloride procured from micro labs, Bangalore. All the chemicals used were of analytical grade and so used without further purification. Distilled water was used for diluting the standard, reagents and samples. All the prepared reagents were stored in the amber colored bottles and protected from direct sunlight. ROPARK, REQUIP and ROPITOR tablets were purchased from local market commercially.

\section{Preparation of standard stock solution}

The standard stock solution $(1 \mathrm{mg} / \mathrm{mL})$ of RPH was prepared by dissolving $100 \mathrm{mg}$ of RPH initially in $10 \mathrm{~mL}$ of $0.1 \mathrm{M}$ sodium hydroxide, followed by dilution to $100 \mathrm{~mL}$ with distilled water. The working standard solution of RPH $(100 \mu \mathrm{g} / \mathrm{mL})$ was obtained by appropriately diluting the standard stock solution with the same solvent. The prepared stock solution was stored at $4{ }^{\circ} \mathrm{C}$ protected from light. From this stock solution, a series of standards were freshly prepared during the analysis day.

\section{Preparation of sample solution}

20 Tablets were weighed accurately to get the average tablet weight and pulverized into fine form. The tablet powder equivalent to $10 \mathrm{mg}$ of $\mathrm{RPH}$ was weighed, dispersed in $25 \mathrm{~mL}$ of methanol, sonicated for $10 \mathrm{~min}$ and filtered through Whatman filter paper no. 41 . The filtrate was evaporated to dryness and the residue was dissolved as under standard solution preparation.

\section{Recommended methods}

\section{Method A}

Aliquots of the working standard RPH solution $(0.5 \mathrm{~mL}, 5.0 \mathrm{~mL}$ and $100 \mu \mathrm{g} / \mathrm{mL})$ were placed in a series of $10 \mathrm{~mL}$ separating funnels. A volume of $0.5 \mathrm{~mL}$ of $1 \mathrm{M}$ hydrochloric acid, 
$2 \mathrm{~mL}$ of $1 \%$ ferric chloride reagent and $0.5 \mathrm{~mL}$ of $0.5 \%$ MBTH reagent were added. The contents were shaken well and diluted up to $10 \mathrm{~mL}$ with distilled water and the intensity of color was measured at $680 \mathrm{~nm}$ (Figure 2) against blank reagent. The calibration curve was plotted by taking concentration $(\mu \mathrm{g} / \mathrm{mL})$ on $\mathrm{x}$-axis and absorbance on $\mathrm{y}$-axis. The amount of drug was computed from its calibration graph.

\section{Method B}

Aliquots of the working standard RPH $(0.5 \mathrm{~mL}, 5.0 \mathrm{~mL}$ and $100 \mu \mathrm{g} / \mathrm{mL})$ were placed in a series of $10 \mathrm{~mL}$ separating funnels. A volume of $1 \mathrm{~mL}$ of freshly prepared $1 \%$ PDAC, $1 \mathrm{~mL}$ of $0.5 \mathrm{M} \mathrm{HCl}$ and then final volume was made up to $10 \mathrm{~mL}$ with distilled water and the intensity of color was measured at $420 \mathrm{~nm}$ (Figure 3) against blank reagent. The calibration curve was plotted by taking concentration $(\mu \mathrm{g} / \mathrm{mL})$ on $\mathrm{x}$-axis and absorbance on y-axis. The amount of drug was computed from its calibration graph.

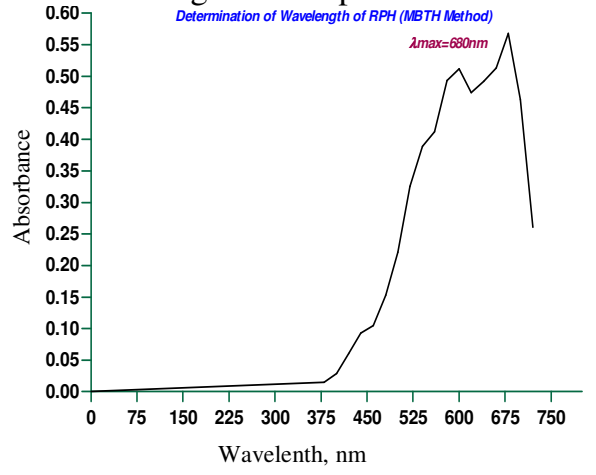

Figure 2. Determination of $\lambda_{\max }$ of RPH (MBTH method)

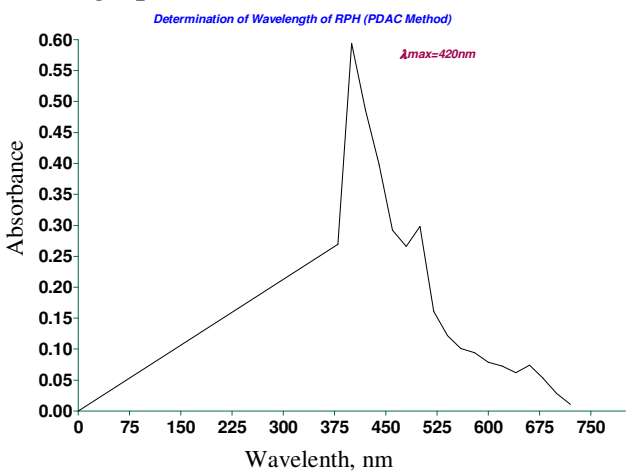

Figure 3. Determination of $\lambda_{\max }$ of $\mathrm{RPH}$ (PDAC method)

\section{Results and Discussion}

The optical characteristics such as Beer's law limit, molar absoptivity, Sandell's sensitivity, slope and intercept are summarized in Table 1.

Table 1. Optical parameters of proposed methods

\begin{tabular}{lcc}
\hline \multicolumn{1}{c}{ Parameter } & Method A & Method B \\
\hline$\lambda_{\text {max }}, \mathrm{nm}$ & 680 & 420 \\
Beer's law limit, $\mu \mathrm{g} / \mathrm{mL}$ & $5-50$ & $5-50$ \\
Sandell's sensitivity, $\mu \mathrm{g} / \mathrm{cm}^{2} / 0.001$ abs. unit & 0.02380 & 0.02739 \\
Molar absorptivity $($ litre/mole/cm) & 22570 & 19160 \\
Correlation coefficient $\left(\mathrm{r}^{2}\right)$ & 0.9999 & 0.9999 \\
Regression equation $(\mathrm{Y}=\mathrm{b}+\mathrm{ac})$ & & \\
Intercept (b) & -0.000518 & -0.001268 \\
Slope (a) & 0.00423 & 0.00366 \\
\% RSD & 0.72528 & 0.98640 \\
$\%$ Range of error & & \\
Confidence limit with 0.05 level & \pm 0.6064 & \pm 0.8248 \\
Confidence limit with 0.01 level & \pm 0.8972 & \pm 1.2200 \\
\hline
\end{tabular}

ROPARK, REQUIP and ROPITOR tablets containing RPH were successfully analyzed and the values obtained by the recommended methods for formulations were compared 
statistically by the $t$ - and $f$-test with reported UV reference method and found not to differ significantly. The assay results for tablets containing RPH are shown in Table 2.

Table 2. Analysis of ropinirole hydrochloride in marketed pharmaceutical dosage forms

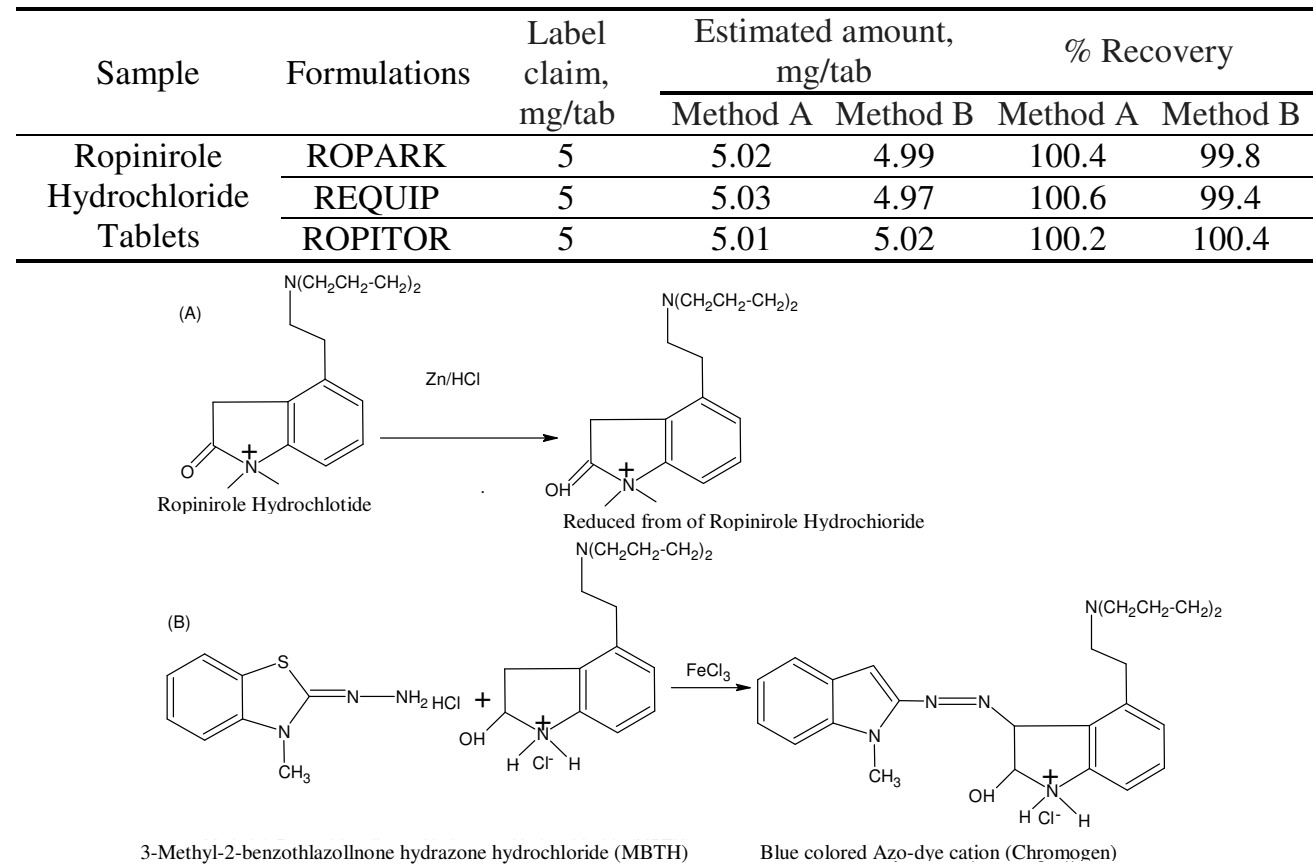

Scheme 1. Recommended method (MBTH method)
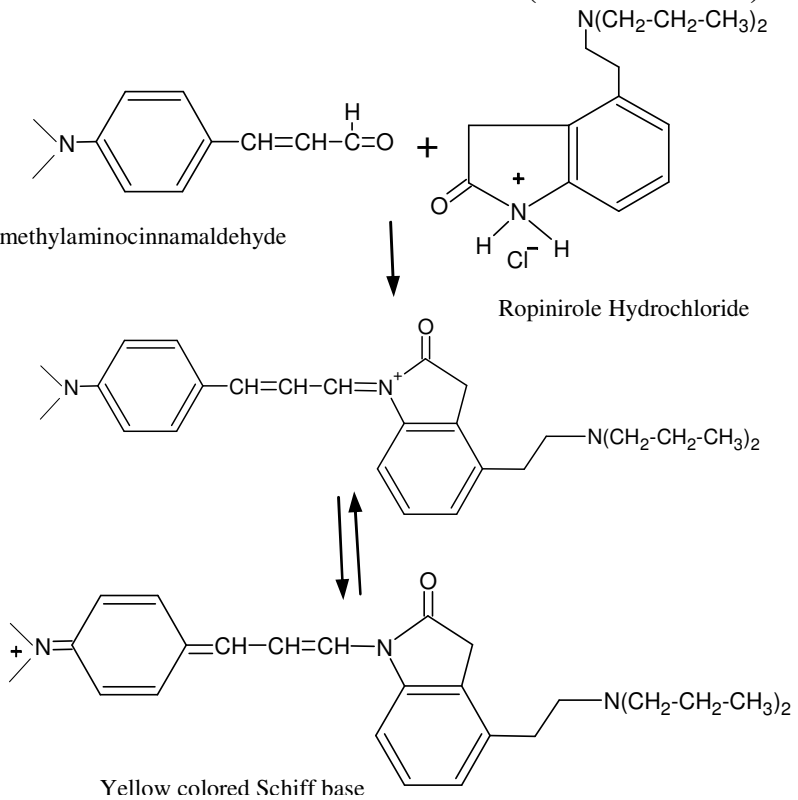

Scheme 2. Recommended method (PDAC method) 


\section{Chemistry of colored species}

In the proposed method-A, the RPH can be reduced under media of zinc and conc. $\mathrm{HCl}$ to get reduced form RPH. Under the specified experimental conditions MBTH on oxidation with ferric chloride looses two electrons and one proton forming an electrophilic intermediate, which is the active couple rapidly with reduced form of $\mathrm{RPH}$ at $3^{\text {rd }}$ position (most active) forming a blue colored azodye cation (Scheme 1). In the method-B, the reaction of PDAC with aromatic amine of the RPH in the presence of strong acid to form yellow colored Schiff base (Scheme 2).

\section{Conclusion}

The recommended methods are applicable for the assay of drug in wider range under Beer's law limits and possess reasonable precision, accuracy and simple, sensitive. The statistical parameters and recovery study data clearly indicate the reproducibility of this method. Analysis of the authentic sample containing RPH showed no interference from the common excipients. Hence, these methods could be considered for the determination of RPH in the quality control laboratories.

\section{References}

1. Raghubabu K, Jagannadharao V and Kalyana Ramu B, Asian J Pharm Anal., 2012, 2, 41-45.

2. Aydogmus Z, Spectrochim Acta A: Mol Biomol Spectrosc., 2008, 70(1), 69-78; DOI:10.1016/j.saa.2007.07.012

3. Susheel J.V, Malathi.S, Ravi T.K., Indian J Pharm Sci., 2007, 69(4), 589-591.

4. Sreekanth N, Babu Rao Ch and Mukkanti K, Int J Pharm Pharm Sci., 2009, 1(1), 186-192.

5. Onal A, Chromatographia, 2006, 64(7-8), 459-461; DOI:10.1365/s10337-006-0045-1

6. Parmar G, Sharma S, Singh K and Bansal G, Chromatographia, 2009, 69(3-4), 199206; DOI:10.1365/s10337-008-0866-1

7. Krishnaiah Ch, Vishnu murthy M, Raghupathi Reddy A, Ramesh Kumar and Mukkanti K, J Chin Chem Soc., 2010, 57, 348-355; DOI:10.1002/jccs.201000052

8. Bhatt J, Jangid A, Shetty R, Shah B, Kambli S, Subbaiah G and Singh S, J Pharm Biomed Anal., 2006, 40(5), 1202-1208; DOI:10.1016/j.jpba.2005.09.024

9. Coufal P, Stulık K, Claessens H A, Hardy M J and Webb M, J Chromatogr B, Biomed Sci Appl., 1999, 732(2), 437-444; DOI:10.1016/S0378-4347(99)00314-X

10. Coufal P, Stulık K, Claessens HA, Hardy M J and Webb M, J Chromatogr B, Biomed Sci Appl., 1998, 720(1-2), 197-204; DOI:10.1016/S0378-4347(98)00427-7

11. Stojanovic B. J, Malenovic A, Ivanovic D, Rakic T and Medenica M, J Chromatogr A, 2009, 1216(8), 1263-1269; DOI:10.1016/j.chroma.2008.10.059

12. ICH, Validation of Analytical Procedures: Methodology, International Conference on Harmonization (IFPMA, Geneva), 1996.

13. ICH, Stability Testing of New Drug Substances and Products, International Conference on Harmonization (IFPMA, Geneva), 2003. 